\title{
EXTRAÇÃO DE ANTIOXIDANTES UTILIZANDO SISTEMAS AQUOSOS BIFÁSICOS COM LÍQUIDOS IÔNICOS COMO ADJUVANTE
}

\author{
R.L. de SOUZA ${ }^{1}$, S.P. VENTURA ${ }^{2}$, C.M.F. SOARES ${ }^{1,3}$, J.A.P. COUTINHO ${ }^{2}$ e A.S. LIMA ${ }^{1,3}$ \\ ${ }^{1}$ Universidade Tiradentes, Instituto de Tecnologia e Pesquisa - ITP, Aracaju, Brasil \\ ${ }^{2}$ Universidade de Aveiro, Departamento de Química, CICECO, Aveiro, Portugal \\ E-mail para contato: alvaro_lima@ unit.br
}

\begin{abstract}
RESUMO - Sistemas aquosos bifásicos (SAB) representam uma excelente técnica para extração/purificação de biocompostos. Os SABs são normalmente formados por polímeros, sais, ou líquidos iônicos (LIs), porém o preço ainda relativamente alto dos LIs e a baixa polaridade dos polímeros limitam sua. Como alternativa, tem-se sugerido a aplicação de LI $(\cong 5 \%, \mathrm{~m} / \mathrm{m})$ para controlar a partição de biomoléculas. Desta forma, o objetivo do trabalho é utilizar o LI como adjuvante na extração de antioxidantes (propil galato e eugenol) em SAB. Foram estudados LIs da família dos imidazólios, conjugados com o ânion cloreto $\left[\mathrm{C}_{\mathrm{n}} \mathrm{mim}\right] \mathrm{Cl}$ $(\mathrm{n}=2$ a 8$)$. Os resultados mostram que as biomoléculas migram para a fase mais hidrofóbica (rica em PEG + LI, $K>1)$ e PEGs de menor massa molecular $(\mathrm{M}=1500)$. A melhor eficiência de extração $(E E)$ do eugenol foi de $99 \%$, em sistemas contendo [ $\left.\mathrm{C}_{6} \mathrm{mim}\right] \mathrm{Cl}$. Para o propil galato, a $E E$ é completa independente da presença ou não de LI ( $E E=100 \%)$, exceto quando aplicado o $\left[\mathrm{C}_{8} \mathrm{mim}\right] \mathrm{Cl}$.
\end{abstract}

\section{INTRODUÇÃO}

Os antioxidantes são compostos fenólicos amplamente utilizados em suplementos alimentares e na área da saúde, devido às suas propriedades de remoção de radicais livres de uma molécula ou organela (Zuo et al., 2002). Antioxidantes fenólicos sintéticos como o propil galato, ou de fontes naturais como o eugenol podem interromper a propagação de reações em cadeia de auto-oxidação (antioxidantes de quebra de cadeia), inibir a formação ou interromper a propagação do radical livre (Brewer 2011).

De modo a desenvolver novos métodos para a extração e concentração de antioxidantes, sistemas aquosos bifásicos (SABs), uma técnica de extração líquido-líquido foi pensada como alternativa para a clássica extração/purificação de compostos e moléculas que incluem os aminoácidos, princípios ativos de medicamentos, compostos fenólicos, enzimas e proteínas que estão presentes em inúmeros processos tecnológicos (Rito-Palomares et al., 2004; Asenjo e Andrews 2012). Os SABs caracterizam-se por remover vários contaminantes de modo simples e econômico, tendo como principais vantagens a sua seletividade mais elevada, a capacidade de adaptação para o processamento da amostra em contínuo e muitas vezes, a manutenção da atividade biológica do composto extraído (Souza et al., 2010).

Geralmente os SABs são compostos por polímeros, sais, carboidratos ou, mais recentemente, por líquidos iônicos (LIs) (Gutowski et al., 2003; Souza et al., 2010, Cardoso et al., 
2013). Para todos os casos, duas fases líquidas são formadas e diversos solutos podem ser distribuídas em cada uma das duas fases aquosas (Graber et al., 2000). São inúmeras as vantagens destes sistemas de extração, no entanto a natureza pouco polar do polímero e o preço relativamente alto dos LIs apresenta-se como um fator limitante no que diz respeito à aplicabilidade desta técnica. Recentemente, SABs utilizando LIs como adjuvantes (usando apenas $5 \%, \mathrm{~m} / \mathrm{m}$ de LI), permitiram um controle mais eficaz dos coeficientes de partição do L-triptofano como biomolécula modelo em sistemas formados por polietileno glicol (PEG) e $\mathrm{Na}_{2} \mathrm{SO}_{4}$ (Pereira et al., 2010). Da mesma forma, Almeida et al. (2014) evidenciam a melhoria na eficiência de extração de compostos fenólicos, como o ácido gálico, ácido vanílico e ácido siríngico nestes mesmos sistemas, porém com PEGs com baixa massa molecular.

O objetivo deste trabalho relaciona a capacidade de SAB à base de PEG e tampão fosfato de potássio $\left(\left[\mathrm{K}_{2} \mathrm{HPO}_{4} / \mathrm{KH}_{2} \mathrm{PO}_{4}\right], \mathrm{pH} 7\right)$, utilizando LIs como adjuvantes $(5 \% \mathrm{~m} / \mathrm{m})$ serem capazes de particionar dois antioxidantes, o propil galato e o eugenol. Neste estudo foram avaliados PEG de massa molecular diferentes $(\mathrm{M}=1500$ e 8000) e LIs da família dos imidazólios, conjugados com o ânion cloreto $\left[\mathrm{C}_{\mathrm{n}} \mathrm{mim}\right] \mathrm{Cl}$ e com diferentes tamanhos de cadeia alquílica, no qual $\mathrm{n}$ onde $\mathrm{n}=2$ a 8 .

\section{DADOS EXPERIMENTAIS}

Os sistemas para extração dos antioxidantes foram formados a partir de $15 \%(\mathrm{~m} / \mathrm{m})$ de PEG $(\mathrm{M}=1500$ ou 8000$),+15 \%(\mathrm{~m} / \mathrm{m})$ de tampão fosfato de potássio $\left(\mathrm{KH}_{2} \mathrm{PO}_{4} / \mathrm{K}_{2} \mathrm{HPO}_{4}\right.$ à $\left.\mathrm{pH} 7\right),+$ $5 \%(\mathrm{~m} / \mathrm{m})$ de cada LI testado (cloreto de 1-etil-3-metilimidazólio - $\left[\mathrm{C}_{2} \mathrm{mim}\right] \mathrm{Cl}$, cloreto de 1-butil3-metilimidazólio - $\left[\mathrm{C}_{4} \mathrm{mim}\right] \mathrm{Cl}$, cloreto de 1-hexil-3-metilimidazólio - $\left[\mathrm{C}_{6} \mathrm{mim}\right] \mathrm{Cl}$ e cloreto de 1octil-3-metilimidazólio - $\left.\left[\mathrm{C}_{8} \mathrm{mim}\right] \mathrm{Cl}\right)$; o propril galato ( $\geq 98 \%$, Sigma Aldrich) e o eugenol (99\%, Sigma Aldrich) foram adicionados em cada sistema na concentração de $\approx 300 \mathrm{mg}$. $\mathrm{L}^{-1}$ para um sistema de $5 \mathrm{~g}$ totais. As concentrações dos constituintes utilizados para formar duas fases aquosas imiscíveis foram confirmadas pelos diagramas de fases descritos por Souza et al. (2014). Os sistemas foram mantidos a $25^{\circ} \mathrm{C}$ durante 12 horas para atingir o equilíbrio. Ambas as fases foram cuidadosamente separadas e pesadas; o volume de cada fase foi registrado, e os antioxidantes foram quantificados utilizando um espectrofotômetro UV-VIS (Shimadzu), a $271 \mathrm{~nm}$ para o propil galato e $279 \mathrm{~nm}$ para o eugenol, por meio de uma curva de calibração previamente determinada para estes compostos.

O coeficiente de partição $(K)$ foi determinado pela razão entre as concentrações de topo e fundo do propil galato ou eugenol (Equação 1); e a eficiência de extração dos antioxidantes (EE, $\%$ ) foi calculada para cada sistema estudado de acordo com a Equação 2,

$$
\begin{gathered}
K=\frac{[\text { Ant }]_{T}}{[\text { Ant }]_{F}} \\
E E=\frac{[\text { Ant }]_{T} \times V_{T}}{[\text { Ant }]_{i} \times V_{i}} \times 100
\end{gathered}
$$

onde: $V$ e $[A n t]$ são o volume e a concentração do antioxidante adicionada para preparar os sistemas de extração, os índices $i$ e $T$ representam a fase inicial e a fase de topo, respectivamente. 


\section{RESULTADOS}

\subsection{Efeito da massa molecular do PEG}

A migração preferencial de solutos/biomoléculas em SAB depende inteiramente das interações específicas e/ou da sua afinidade para uma dada fase (Shang et al., 2004; Salabat et al., 2011). Previamente dois PEGs com massas moleculares distintas $(M=1500$ e 8000) foram utilizados para avaliar a extração dos antioxidantes em SAB compostos por PEG + $\mathrm{K}_{2} \mathrm{HPO}_{4} / \mathrm{KH}_{2} \mathrm{PO}_{4}$, de $\mathrm{pH} 7$.

O propil galato e o eugenol (Figura 1a) particionaram-se preferencialmente para a fase rica em polímero com $(K>1)$. Os coeficientes de partição dos antioxidantes para o sistema PEG 1500 $+\mathrm{K}_{2} \mathrm{HPO}_{4} / \mathrm{KH}_{2} \mathrm{PO}_{4}$, são de $104,8 \pm 7,4$ e 40,9 $\pm 7,0$, respectivamente para o propil galato e eugenol. Na Figura $1(b)$, a $E E$ dos antioxidantes para fase mais hidrofóbica (rica em PEG) foi reforçada com PEG de menor massa molecular (PEG 1500), a EE do propil galato aumentou de 95 para $100 \%$, e nesta mesma condição, a $E E$ do eugenol passou de 80 para $94 \%$. O perfil desta migração preferencial segue um padrão semelhante ao relatado anteriormente com uma clara preferência dos antioxidantes para a fase mais hidrofóbica (Santos et al., 2010), e confirmado por seus coeficientes de partição octanol - água $\left(K_{\mathrm{ow}}\right)$ : propil galato $\left(K_{\mathrm{ow}}=1,8\right)$ e do eugenol $\left(K_{\mathrm{ow}}=\right.$ 2,27). Corroborando estes resultados, Almeida et al. (2014) descreve o uso de PEGs menores como os melhores para a partição do ácido gálico $(E E=95 \%)$, ácido vanílico $(E E=96 \%)$ e ácido siríngico $(E E=96 \%)$ utilizando SAB com base em PEG 300 e $\mathrm{Na}_{2} \mathrm{SO}_{4}$. Embora as duas biomoléculas sejam de caráter hidrofóbico e migrem para fase rica em $\mathrm{PEG}$, a menor $E E$ do eugenol pode estar relacionada ao $\mathrm{pH}$ da fase de fundo rica em sal $\left(\mathrm{K}_{2} \mathrm{HPO}_{4} / \mathrm{KH}_{2} \mathrm{PO}_{4}, \mathrm{pH} \approx 7\right)$ com sua maior constante de dissociação $(\mathrm{p} K \mathrm{a}=9,94)$ comparado ao do propil galato $(\mathrm{p} K \mathrm{a}=8,11)$ (Wishart et al., 2013). De fato, espécies carregadas tendem a migrar para a fase rica em sal enquanto que moléculas neutras particionam preferencialmente para a fase mais hidrofóbica e menos carregada.

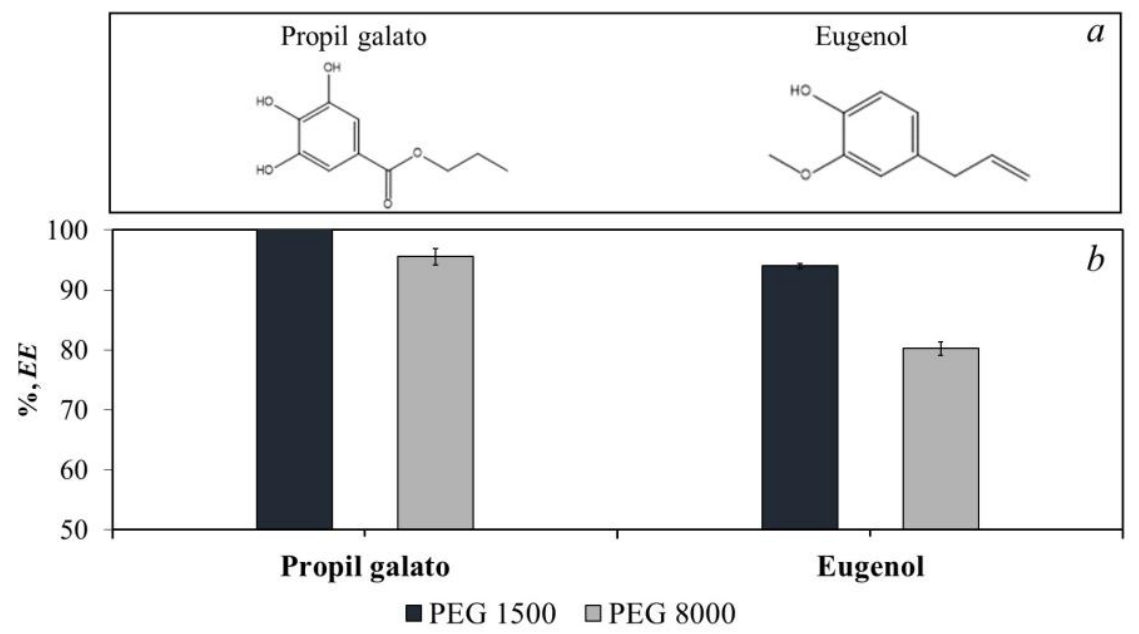

Figura $1-i$ ) Estrutura molecular do propil galato e do eugenol; $i$ i) Efeito da massa molecular do PEG na eficiência de extração $(E E)$ do propil galato e do eugenol em SAB compostos por PEG + $\left[\mathrm{K}_{2} \mathrm{HPO}_{4} / \mathrm{KH}_{2} \mathrm{PO}_{4}\right]$ à temperatura de $25^{\circ} \mathrm{C}$. 


\subsection{Efeito do LI}

SAB utilizando líquidos iônicos como adjuvante $(5 \%, \mathrm{~m} / \mathrm{m})$ para a extração de compostos antioxidantes, são uma alternativa para melhorar o desempenho da extração dos sistemas estudados. Os LIs com diferentes comprimentos de cadeia alquílica do cátion imidazólio conjugado com ânion cloreto $\left[\mathrm{C}_{n} \mathrm{mim}\right] \mathrm{Cl}(n=2$ a 8$)$ foram adicionados em SAB com base em $\mathrm{PEG}+\mathrm{K}_{2} \mathrm{HPO}_{4} / \mathrm{KH}_{2} \mathrm{PO}_{4}$ e testados para a extração do propil galato e do eugenol.

A EE do propil galato utilizando PEG 1500 (Figura 2) foi sempre completa para a fase de topo em todos os sistemas testados, seja ele com ou sem LI, com exceção do sistema aditivado com $\left[\mathrm{C}_{8} \mathrm{mim}\right] \mathrm{Cl}$ que por fenômenos associados à formação de micelas possui um desvio da tendência esperado (Passos et al., 2013). Porém, nos sistemas formados com PEG 8000, para os dois antioxidantes (Figuras 2 e 3), é possível observar melhor o efeito na $E E$ com o aumento da cadeia alquílica do LI, que segue a seguinte tendência: $\left[\mathrm{C}_{2} \mathrm{mim}\right] \mathrm{Cl}<\left[\mathrm{C}_{4} \mathrm{mim}\right] \mathrm{Cl}<\left[\mathrm{C}_{6} \mathrm{mim}\right] \mathrm{Cl}$, o $\mathrm{LI}\left[\mathrm{C}_{8} \mathrm{mim}\right] \mathrm{Cl}$ novamente aparece como exceção. Este efeito é mais claramente observado na Figura 3, para a extração do eugenol.

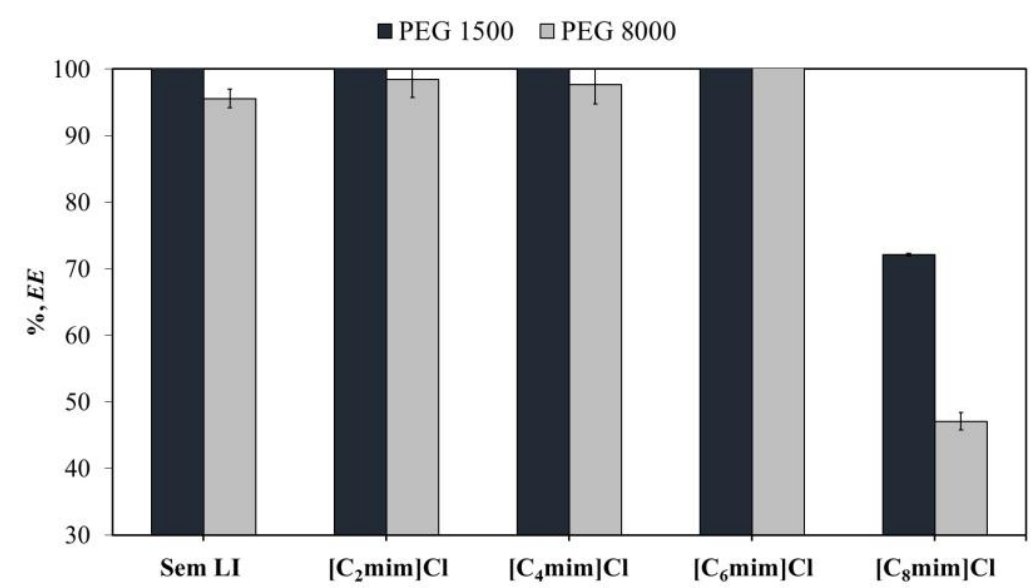

Figura 2 - Eficiência de extração $(E E)$ do propil galato em SAB com base em PEG + $\left[\mathrm{K}_{2} \mathrm{HPO}_{4} / \mathrm{KH}_{2} \mathrm{PO}_{4}\right]+\mathrm{IL}$ (como adjuvante) à $25^{\circ} \mathrm{C}$.

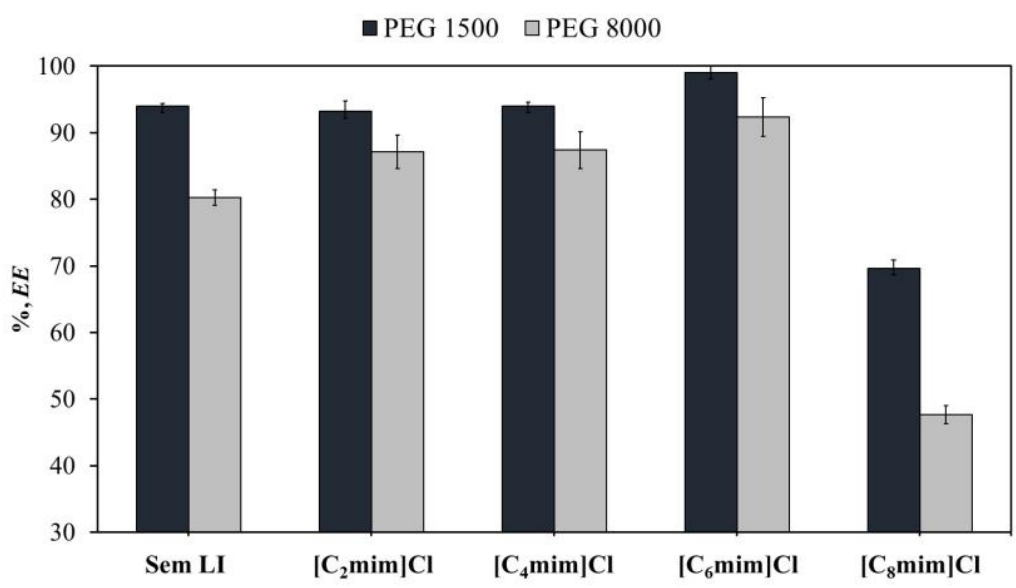

Figura 3 - Eficiência de extração $(E E)$ do propil galato em $\mathrm{SAB}$ à base de $\mathrm{PEG}+$ $\left[\mathrm{K}_{2} \mathrm{HPO}_{4} / \mathrm{KH}_{2} \mathrm{PO}_{4}\right]+\mathrm{IL}$ (como adjuvante) à $25^{\circ} \mathrm{C}$. 
Pela observação da Figura 3 é possível verificar o efeito do LI na $E E$ do eugenol. A $E E$ foi melhorada (de $94 \pm 0.38$ para $99 \pm 3.06 \%$ ) utilizando o $\left[\mathrm{C}_{6} \mathrm{mim}\right] \mathrm{Cl}$ em sistema com PEG 1500. Para compreender este efeito, as interações entre o polímero e os LIs também são relevantes, visto que, não somente há migração entre as fases dos antioxidantes, mas também do LI adicionado ao SAB (Pereira et al., 2012; Almeida et al., 2014). Os valores da eficiência de extração denotam uma partição preferencial para a fase rica em polímero e quando presente, rica igualmente em LI. Neste sentido, a maior hidrofobicidade desta fase polimérica, dita a partição também quando aditivada com Lis cuja cadeia alquílica vai aumentando o tamanho. Na verdade, essas tendências estão intimamente relacionadas com o comportamento binário de miscibilidade entre PEG-IL e com a respectiva capacidade de formação SAB (Freire et al., 2012). Neste sentido, a migração de LI preferencial para a fase superior do sistema irá naturalmente alterar as propriedades químicas e físicas da fase rica em polímero, permitindo ocorrer interações específicas como entre polímero+sal+água+antioxidante.

\section{CONCLUSÃO}

$\mathrm{O}$ uso de LIs como adjuvantes em SAB convencionais PEG $+\left[\mathrm{K}_{2} \mathrm{HPO}_{4} / \mathrm{KH}_{2} \mathrm{PO}_{4}\right]$ para melhorar a extração de produtos de valor agregado, tais como antioxidantes, é aqui proposto. Os resultados sugerem que os antioxidantes (propil galato e eugenol) tem uma maior afinidade para a fase mais hidrofóbica (fase rica em PEG) de peso moleculares menores (PEG 1500) em SAB convencional formado por PEG e sais. No entanto, SAB com base em PEG + sal + LI + água proporcionam eficiências de extração melhoradas, especialmente com o $\left[\mathrm{C}_{6} \mathrm{mim}\right] \mathrm{Cl}$ para a extração do eugenol $(E E=99 \%)$. Para o propil galato, a $E E$ é completa e em geral, independente do uso de LI em SAB à base de PEG $1500(E E=100 \%)$, sendo o $\left[\mathrm{C}_{8} \mathrm{mim}\right] \mathrm{Cl}$ a exceção a este comportamento, pela sua auto-agregação e consequente formação de agregados.

\section{REFERENCIAS}

ALMEIDA, M. R.; PASSOS, H.; PEREIRA, M. M.; LIMA, A. S.; COUTINHO, J. A. P.; FREIRE, M. G. Ionic liquids as additives to enhance the extraction of antioxidants in aqueous two-phase systems. Sep Purif Technol, v. 128, p. 1-10, 2014.

ASENJO, J. A.; ANDREWS, B. A. Aqueous two-phase systems for protein separation: Phase separation and applications. J Chromatogr A, v. 1238, p. 1-10, 2012.

BREWER, M. S. Natural Antioxidants: Sources, Compounds, Mechanisms of Action, and Potential Applications. Compr Rev Food Sci F, v.10, p. 221-247, 2011.

CARDOSO, G.B; MOURÃO, T.; PEREIRA, F. M.; FREIRE, M. G.; FRICKS, A. T.; SOARES, C. M. F.; LIMA, A. S. Aqueous two-phase systems based on acetonitrile and carbohydrates and their application to the extraction of vanillin. Sep Purif Technol, v. 104, p. 106-113, 2013.

FREIRE, M. G.; PEREIRA, J. F. B.; FRANCISCO, M.; RODRIGUEZ, H.; REBELO, L. P. N.; ROGERS, R. D.; COUTINHO, J. A. P. Insight into the Interactions That Control the Phase Behaviour of New Aqueous Biphasic Systems Composed of Polyethylene Glycol Polymers and Ionic Liquids. Chem-Eur J, v. 18, p. 1831-1839, 2012. 
GRABER, T. A.; TABOADA, M. E.; CARTON, A.; BOLADO, S. Liquid-liquid equilibrium of the poly(ethylene glycol) plus sodium nitrate plus water system at $298.15 \mathrm{~K}$. J Chem Eng Data, v. 45 , p. 182-184, 2000.

GUTOWSKI, K. E., BROKER, G. A., WILlAUER, H. D., HUDDLESTON, J. G., SWATLOSKI, R. P.; HOLBREY, J. D.; ROGERS, R. D. Controlling the aqueous miscibility of ionic liquids: Aqueous biphasic systems of water-miscible ionic liquids and water-structuring salts for recycle, metathesis, and separations. J Am Chem Soc, v. 125, p. 6632-6633, 2003.

MERCHUK, J. C.; ANDREWS, B. A.; ASENJO, J. A. Aqueous two-phase systems for protein separation: Studies on phase inversion. J. Chromatogr. B, v. 711, p. 285-293, 1998.

PASSOS, H.; TRINDADE, M. P.; VAZ, T. S. M.; DA COSTA, L. P.; FREIRE, M. G.; COUTINHO, J. A. P. The impact of self-aggregation on the extraction of biomolecules in ionicliquid-based aqueous two-phase systems. Sep Purif Technol, v. 108, p. 174-180, 2013.

PEREIRA, J. F. B.; LIMA, A. S.; FREIRE, M. G.; COUTINHO, J. A. P. Ionic liquids as adjuvants for the tailored extraction of biomolecules in aqueous biphasic systems. Green Chem, v.12, p. 1661-1669, 2010.

RITO-PALOMARES, M. (2004) Practical application of aqueous two-phase partition to process development for the recovery of biological products. J Chromatogr B, v. 807, p. 3-11, 2004.

SALABAT, A., SADEGHI, R., MOGHADAM, S. T. \& JAMEHBOZORG, B. (2011) Partitioning of L-methionine in aqueous two-phase systems containing poly(propylene glycol) and sodium phosphate salts. J Chem Thermodyn, v. 43, p. 1525-1529, 2011.

SOUZA, R. L.; BARBOSA, J. M. P.; ZANIN, G. M.; LOBAO, M. W. N.; SOARES, C. M. F.; LIMA, A. S. Partitioning of Porcine Pancreatic Lipase in a Two-Phase Systems of Polyethylene Glycol/Potassium Phosphate Aqueous. Appl Biochem Biotech, v.161, p. 288-300, 2010.

SOUZA, R.L.; CAMPOS, V. C.; VENTURA, S. P. M.; SOARES, C. M. F.; COUTINHO, J. A. P.; LIMA, A. S. Effect of ionic liquids as adjuvants on PEG-based ABS formation and the extraction of two probe dyes. J. Fluid Phases, In Press (2014). 